\title{
The Frequency of Rectovaginal Group B Streptococci in Third Trimester Pregnant Women and Affecting Factors
}

\section{Son Trimester Gebelerin Rektovajinal Grup B Streptokok Koloni Sıklığı ve Etkileyen Faktörler}

\author{
${ }^{1}$ Çekerek Aile Sağlığı Merkezi, Çekerek, Yozgat, Türkiye \\ ${ }^{2}$ Karabük Üniversitesi, Tıp Fakültesi, Aile Hekimliği A.D., Karabük, Türkiye. \\ ${ }^{3}$ Yıldızeli Aile Sağ lığı Merkezi, Yıldızeli, Sivas, Türkiye. \\ ${ }^{4}$ Cumhuriyet Üniversitesi, Tıp Fakültesi, Aile Hekimliği A.D., Sivas, Türkiye
}

Pınar Kalpakçı ${ }^{1}$, Ali Ramazan Benli ${ }^{2}$, Selman Erturhan ${ }^{3}$, Yeltekin Demirel ${ }^{4}$

\section{öz}

Amaç: Gebelikte rektovajinal Grup B streptokoklar (GBS) morbidite ve mortaliteye neden olan etkenlerden biridir. Genellikle asemptomatik seyreder ancak idrar yolu enfeksiyonlarından sepsise kadar geniş enfeksiyonlara neden olabilir. Bu çalışmada da son trimester gebelerinin GBS sıklığı ve ilişkili durumlar araştırılmıştır.

Materyal ve Metod: Tıp Fakültesi Hastanesi Kadın Hastalıklar ve Doğum Anabilim Dalı Polikliniği'ne başvuran ve gestasyone haftası 30 hafta ve üzeri olan gebelerden vajinal ve anorektal sürüntü örnekleri alınarak kültür antibiyogramları bakıldı. Verilerin analizinde tanımlayıcı istatistikler, ki- kare, t-student ve Mann Whitney $\mathrm{U}$ testleri kullanıldı. $\mathrm{p}<0,05$ istatistiksel olarak önemli kabul edildi.

Bulgular: Çalışmaya alınan 214 gebenin 17 'sinde (\%7.9) grup B streptokok üremesi oldu. Gebelerde GBS kolonizasyon sıklığı ile yaş grupları, eğitim durumları, ikamet yerleri, sosyo-ekonomik düzey, gestasyonel öykü, hipertansiyon ve diyabet öyküsü, sigara ve RiA kullanımı karşılaştıııldığında anlamlı bir fark bulunamadı. İncelenen gebelerde menstrüel siklusları düzensiz olanlarda, gebelik öncesi herhangi bir doğum kontrol yöntemini kullananlarda ve ilk gebelik yaşı yüksek olanlarda, GBS'lerin rekto-vajinal üreme sıklığı yüksek bulundu. Alınan kültür örneklerinde grup B streptokok dışında \%27.5'inde Stafilokokus epidermidis, \%25.7'sinde Enterococcus faecalis, \%20.9'unda Candida albicans üredi.

Sonuç: Illk gebelik yaşı yüksek olan, menstrüel siklus düzensizliğ yaşayan ve doğum kontrol yöntemi kullanan kadınlarda grup $B$ Streptokok üremesinde artış gözlemlenmesi sebebiyle; bu parametreleri esas alan daha geniş kapsamlı çalışmalara ihtiyaç vardır. Yenidoğanda erken başlangıçlı enfeksiyonları önlemek için gebe tarama programları arasında yer alan grup B streptokok taramasının rutin gebe izlem programına dâhil edilmesi gerekmektedir.

Anahtar Kelimeler: Streptokokus agalactia, 3. trimester, Gebe tarama programı

\section{ABSTRACT}

Aim: Rectovaginal Group B Streptococci (GBS) colonization is one of the reasons of the mortality and morbidity in pregnancy. It generally seems asymptomatic but cause to wide infection from urinary infection to sepsis. GBS frequency was investigated in third trimester of pregnant women in this study.

Materials and methods: The study was done in the autpatient clinic of medical faculty gynecology and obstetric department. Vaginal and anorectal swab was taken from pregnant women who are 30 weeks or more gestational age. Descriptive statistics, chi-square, student-t and Mann-Whitney $U$ test was used in the analyzing the data and $p<0.05$ was considered statistically significant.

Results: In the study of 214 pregnant women, 17 (7.9\%) of GBS was reproduction. There was no significance the incidence of GBS colonization in pregnant women with educational status, living space, socio-economic status, gestational history, hypertension, diabetes, smoking and use of intrauterin device. We found higher incidence of GBS colonization in pregnants with irregular menstrual cycles, using any method of birth control before pregnancy and higher age of first pregnancy. It produced $27.5 \%$ of Staphylococcus epidermidis, $25.7 \%$ of Enterococcus faecalis, $20.9 \%$ of Candida albicans in samples except GBS in the microbial culture.

Conclusion: Because of GBS colonization increase in pregnant women whose age of first pregnancy is high, menstruel cycles are irregular and using birth control methods, comprehensive studies are needed with these parameters. GBS screening should be incorporated into routine prenatal follow the program for avoid newborn infection.

Keywords: Streptococci agalactiae, Third trimester, Pregnant screening program 


\section{GİRIŞ}

Grup B streptokoklar (GBS) neonatal dönemde morbidite ve mortaliteye neden olan etkenlerden biridir. Genellikle asemptomatik seyredebilen GBS, gebe kadındalarda rektovajinal kolonizasyon sonrası koryoamniyonit, idrar yolu enfeksiyonu, bakteriyemi gibi değişik klinik formlarda enfeksiyonlara neden olmaktadır. Doğum sırasında yenidoğana bulaşabilmekte ve yenidoğanda menenjit, osteomyelit, sepsis gibi yüksek oranda mortalite ve morbidite ile seyreden ciddi enfeksiyonlara yol açabilmektedir (1).

Amerika Birleşik Devletlerinde GBS neonatal mortalite ve morbiditenin başlica sebeplerinden biri olması üzerine 2010 y1linda, CDC (Centers for Disease Control and Prevention) ACOG (American College of Obstetricians and Gynecologists) ve AAP ( American Academy of Pediatrics) birlikte hastalığın önlenmesine yönelik bir kılavuz yayımlamıştır (2). AAFP (Association American Family Physicion) 2012 y1lında CDC kılavuzunu yeniden düzenlemiştir. Revize edilen k1lavuza göre; 35-37 haftalık gebe kadınların rekto-vajinal GBS taşıyıcılığı açısından taranması gerektiği vurgulanmış ve kültür sonucu olumlu bulunan veya nükleik asit testin pozitif olan gebelere antibiyotik profilaksisi önerilmiştir. Erken membran rüptürü ve erken doğum olgularının diğer normal gebelerden ayrılması gerektiği de vurgulanmıştır (3). Bu çalışmada; son trimester gebe kadınlarda vajinal ve anorektal grup B streptokok (Streptococcus agalactiae, GBS) kolonizasyon siklığının sosyodemografik özellikler, menstrüel siklus, sigara kullanımı, rahim içi araç (RİA) kullanımı, gebelik öyküsü ile karşılaştırılması amaçlanmıştır.

\section{GEREÇ VE YÖNTEM}

$\mathrm{Bu}$ çalışma tanımlayıcı ve kesitsel bir çalışmadır. Cumhuriyet Üniversitesi Tıp Fakültesi Hastanesi Kadın Hastalıkları ve Doğum Anabilim Dalı Polikliniği'ne Kasım 2013 - Nisan 2014 tarihleri arasında herhangi bir nedenle başvuran ve gestasyonel haftası 30 hafta ve üzeri olan gebelere sosyodemografik anket uyguland. Gebelerden muayene masasında litotomi pozisyonunda iki ayr1 steril eküvyon çubuğu (transport swab) ile vajinal ve anorektal sürüntü örnekleri alındı. Vajinal örnekler vajinanın alt 1/3'ünden, anorektal örnekler ise anal sfinkterden $2 \mathrm{~cm}$ rektuma doğru ilerletilerek ve 360 derece çevrilerek alındı. Sürüntü örnekleri, $1 \mathrm{ml}$ 'de 0.8 mikrogram gentamisin ve 1 ml'de 15 mikrogram nalidiksik asit içeren seçici ToddHewitt sivi besiyerinde $35^{\circ} \mathrm{C}$ 'de aerop ortamda 18-24 saat inkübe edildi. Üreyen bakterilerin kanlı agara subkültürleri yapıldı. Kanlı agarda beta hemolitik olan veya GBS olduğundan şüphelenilen koloniler ileri testlere tabi tutuldu. Gram boyama, katalaz reaksiyonu, siklik adenozin monofosfat (C-AMP) reaksiyonu, basitrasin ve trimetoprim sulfometaksazole duyarlılık, hipürat hidrolizi, safralı eskülinli agarda üreme özelliklerine bakıldı. GBS lateks aglütinasyon testi ile sonuç teyit edildi.

Verilerin analizinde SPSS (Statistical Package for Social Sciences for Windows) 20 yazılım programı kullanıldı. Verilerin değerlendirilmesinde tanımlayıcı istatistikler yüzde ve frekans olarak verildi. Parametrelerin karşılaştırılmasında ki- kare, student-t ve Mann Whitney $U$ testleri kullanıldı. $\quad \mathrm{P}<0,05$ istatistiksel olarak önemli kabul edildi.

$\mathrm{Bu}$ çalışma, Cumhuriyet Üniversitesi Klinik Araştırmalar Etik Kurulu' nun 03.09.2013 tarih ve 2013-09/01 sayılı kararı ile yapılmıştır.

\section{BULGULAR}

Çalışmaya gestasyonel haftası 30 ve üzeri olan 214 gebe dâhil edildi. Gebelerin \%7.9' unda $(\mathrm{n}=17)$ grup $\mathrm{B}$ streptokok üremesi oldu.

Olguların demografik özellikleri Tablo 1. de gösterilmiştir.

Araştırmaya katılan 214 gebenin sosyal özellikleri ve bu özelliklere göre GBS üremesi arasındaki ilişki Tablo 2. de gösterilmiştir. 
Gebelerin ikiz gebelik durumları, son on gün içinde antibiyotik kullanım öyküleri, $\mathrm{Rh}$ uygunsuzluğu durumları, sigara kullanma, rahim içi araç kullanım durumları ve önceki gebeliklerinde erken doğum öyküsü varlığı ile GBS arasındaki ilişki Tablo 3 . de gösterilmiştir.

Tablo 1. Gebelerin Demografik Özelliklerinin Dağılımı

\begin{tabular}{|l|c|c|c|c|c|c|}
\hline Değișken & $\mathbf{n}$ & Min. & $\begin{array}{c}\text { Max } \\
\cdot\end{array}$ & Ortalama & $\begin{array}{c}\text { Ortanc } \\
\mathbf{a}\end{array}$ & SD \\
\hline Yaș & 214 & 18 & 47 & 29,48 & 29 & 5,584 \\
\hline $\begin{array}{l}\text { Evlendiği } \\
\text { yaș }\end{array}$ & 214 & 14 & 36 & 21,27 & 20 & 4,403 \\
\hline $\begin{array}{l}\text { Evlilik } \\
\text { süresi }\end{array}$ & 214 & 1 & 27 & 7,85 & 7 & 6,014 \\
\hline $\begin{array}{l}\text { Menarș } \\
\text { yașı }\end{array}$ & 214 & 10 & 18 & 13,32 & 13 & 1,160 \\
\hline $\begin{array}{l}\text { Gebelik } \\
\text { haftası }\end{array}$ & 214 & 30 & 40 & 35,23 & 35,5 & 2,717 \\
\hline Gravida & 214 & 1 & 12 & 2,98 & 3 & 1,779 \\
\hline Parite & 214 & 0 & 8 & 1,47 & 1 & 1,277 \\
\hline Yașayan & 214 & 0 & 8 & 1,36 & 1 & 1,232 \\
\hline Abortus & 214 & 0 & 7 & 0,46 & 0 & 1,033 \\
\hline $\begin{array}{l}\text { Intrauterin } \\
\text { Ex }\end{array}$ & 214 & 0 & 2 & 0,14 & 0 & 0,369 \\
\hline $\begin{array}{l}\text { İlk gebelik } \\
\text { yașı }\end{array}$ & 214 & 15 & 37 & 22,39 & 21 & 4,404 \\
\hline
\end{tabular}

SD: Standart Deviasyon
Gebelerin \%9,3' ünde $(\mathrm{n}=20)$ hipertansiyon mevcutken, \%13,1' inde ise $(\mathrm{n}=28)$ gestasyonel diyabet vard1. Kadınların hipertansiyon öyküleri ile GBS üreme durumları arasında istatistiksel olarak anlamlı bir ilişki yoktu (Fisher'in Kesin Testi, p= 0,378). Çalışmamızda, gestasyonel diyabeti olan gebelerin GBS kolonizasyonu, diyabeti olmayan gebelere göre 2,21 kat yüksek bulunmuştur. Fakat GBS üremesi ile gestasyonel diyabet arasında istatistiksel olarak anlamlı bir ilişki saptanamadı (Fisher'in Kesin Testi, $\mathrm{p}=0$,250) (Tablo 3).

Örnek alınan gebelerin \%55,1' i (n=118) gebeliklerini planlamadan önce doğum kontrol yöntemi kullanmaktaydı. Bunların \%10,2' si $(n=22)$ oral kontraseptif, \%11,7' si $(n=25)$ RİA，\%33,2' si $(n=71)$ diğer yöntemleri kullaniyordu (Tablo 4). Gebelerin \%44,9' s1 $(n=96)$ ise herhangi bir doğum kontrol yöntemi kullanmiyordu.

Tablo 2. Gebelerin Sosyal ve Medikal Özelliklerinin GBS Üremesi ile Karşılaştırılması

\begin{tabular}{|c|c|c|c|c|c|}
\hline \multirow{2}{*}{\multicolumn{2}{|c|}{ Değgișken }} & \multicolumn{2}{|c|}{ GBS üremesi } & \multirow[t]{2}{*}{ Toplam } & \multirow[t]{2}{*}{ p değeri* } \\
\hline & & Var & Yok & & \\
\hline \multirow[t]{3}{*}{ İkamet } & Şehir & $12(\% 5,6)$ & $130(\% 60,7)$ & $142(\% 66,3)$ & \multirow{3}{*}{0,587} \\
\hline & İlçe & $4(\% 1,9)$ & $38(\% 17,8)$ & $42(\% 19,7)$ & \\
\hline & Köy & $1(\% 0,5)$ & $29(\% 13,5)$ & $30(\% 14,0)$ & \\
\hline \multirow[t]{6}{*}{ Eğitim } & Okuryazar değil & $0(\% 0,0)$ & $8(\% 3,7)$ & $8(\% 3,7)$ & \multirow{6}{*}{0,698} \\
\hline & Okuryazar & $1(\% 0,5)$ & $5(\% 2,3)$ & $6(\% 2,8)$ & \\
\hline & İlkokul mezunu & $7(\% 3,3)$ & $63(\% 29,5)$ & $70(\% 32,8)$ & \\
\hline & $\begin{array}{l}\text { Ortaokul } \\
\text { mezunu }\end{array}$ & $3(\% 1,4)$ & $48(\% 22,4)$ & $51(\% 23,8)$ & \\
\hline & Lise mezunu & $2(\% 0,9)$ & $40(\% 18,7)$ & $42(\% 19,6)$ & \\
\hline & $\begin{array}{l}\text { Üniversite } \\
\text { mezunu }\end{array}$ & $4(\% 1,9)$ & $33(\% 15,4)$ & $37(\% 17,3)$ & \\
\hline \multirow[t]{2}{*}{ Meslek } & Çalışıyor & $4(\% 1,9)$ & $31(\% 14,5)$ & $35(16,4)$ & \multirow{2}{*}{0,490} \\
\hline & Çalıșmiyor & $13(\% 6,1)$ & $166(\% 77,5)$ & $179(\% 83,6)$ & \\
\hline \multirow{3}{*}{$\begin{array}{l}\text { Aylık toplam } \\
\text { gelir }\end{array}$} & $<804 \mathrm{TL}$ & $2(\% 0,9)$ & $61(\% 28,5)$ & $63(\% 29,4)$ & \multirow{3}{*}{0,214} \\
\hline & 804-2000 TL & $10(\% 4,7)$ & $99(\% 46,3)$ & $109(\% 51)$ & \\
\hline & $>2000 \mathrm{TL}$ & $5(\% 2,3)$ & $37(\% 17,3)$ & $42(\% 19,6)$ & \\
\hline \multirow{2}{*}{$\begin{array}{l}\text { Menstrüel } \\
\text { siklus }\end{array}$} & Düzenli & $11(\% 5,2)$ & $167(\% 78,0)$ & $178(\% 83,2)$ & \multirow{2}{*}{0,045} \\
\hline & Düzensiz & $6(\% 2.8)$ & $30(\% 14,0)$ & $36(\% 16,8)$ & \\
\hline \multirow{3}{*}{$\begin{array}{l}\text { Infertilite } \\
\text { tedavisi }\end{array}$} & IVF & $1(\% 0,5)$ & $3(\% 1,4)$ & $4(\% 1,9)$ & \multirow[t]{3}{*}{$* *$} \\
\hline & $\begin{array}{l}\text { Çatlatma iğnesi } \\
\text { (HCG) }\end{array}$ & $0(\% 0,0)$ & $1(\% 0,5)$ & $1(\% 0,5)$ & \\
\hline & Aşıllama & $1(\% 0,5)$ & $0(\% 0,0)$ & $1(\% 0,5)$ & \\
\hline
\end{tabular}

*Ki kare testi $\quad * *$ Yetersiz veri 
Kadınların doğum kontrol yöntemi kullanma durumlariyla GBS üreme durumları arasında istatistiksel olarak anlamlı düzeyde fark vard1 $(\mathrm{p}=0,019)$ (Tablo 5). Doğum kontrol yöntemi kullanan kadınlarda GBS üreme durumu daha yüksekti.
Örnek alınan 214 gebenin \%7,9' unda $(\mathrm{n}=17)$ GBS üredi. GBS üreyen gebelerin 8 'inde $(\% 47,1)$ sadece vajinada, 2'sinde $(\% 11,7)$ sadece anorektal bölgede üreme olurken, 7 $(\% 41,2)$ gebede ise her iki bölgede de üreme oldu.

Tablo 3. Gebelerin Komorbid Durumlarının GBS Üremesi İle Karșılaștırılması

\begin{tabular}{|c|c|c|c|c|c|}
\hline \multicolumn{2}{|l|}{ Değişken } & \multicolumn{2}{|c|}{ GBS üreme } & \multirow{2}{*}{$\begin{array}{l}\text { Toplam } \\
6(\% 2,8) \\
\end{array}$} & p değeri* \\
\hline \multirow[t]{2}{*}{ Çoklu gebelik } & Var & $\begin{array}{c}\text { Var } \\
0(\% 0,0) \\
\end{array}$ & $\begin{array}{c}\text { Yok } \\
6(\% 2,8) \\
\end{array}$ & & \multirow{2}{*}{1,00} \\
\hline & Yok & $17(\% 7,9)$ & $191(\% 89,3)$ & $208(\% 97,2)$ & \\
\hline \multirow{2}{*}{$\begin{array}{l}\text { Son } 10 \text { gün içinde } \\
\text { antibiyotik } \\
\text { kullanımı }\end{array}$} & Var & $1(\% 0,5)$ & $21(\% 9,8)$ & $22(\% 10,3)$ & \multirow{2}{*}{1,00} \\
\hline & Yok & $16(\% 7,5)$ & $176(\% 82,2)$ & $192(\% 89,7)$ & \\
\hline \multirow[t]{2}{*}{ Rh uygunsuzluğu } & Var & $1(\% 0,5)$ & $15(\% 7)$ & $16(\% 7,5)$ & \multirow{2}{*}{1,00} \\
\hline & Yok & $16(\% 7,5)$ & $182(\% 85)$ & $198(\% 92,5)$ & \\
\hline \multirow[t]{3}{*}{ Sigara kullanımı } & Kullanıyor & $1(\% 0,5)$ & $18(\% 8,4)$ & $19(\% 8,9)$ & \multirow{3}{*}{0,240} \\
\hline & Kullanmiyor & $13(\% 6,1)$ & $166(\% 77,5)$ & $179(\% 83,6)$ & \\
\hline & Birakmıș & $3(\% 1,4)$ & $13(\% 6,1)$ & $16(\% 7,5)$ & \\
\hline \multirow[t]{2}{*}{ RİA kullanımı } & Var & $3(\% 1,4)$ & $22(\% 10,3)$ & $25(\% 11,7)$ & \multirow{2}{*}{0,428} \\
\hline & Yok & $14(\% 6,5)$ & $175(\% 81,8)$ & $189(\% 88,3)$ & \\
\hline \multirow{2}{*}{$\begin{array}{ll}\text { Erken } & \text { doğum } \\
\text { öyküsü } & \\
\end{array}$} & Var & $1(\% 0,5)$ & $31(\% 14,5)$ & $32(\% 15)$ & \multirow{2}{*}{0,479} \\
\hline & Yok & $16(\% 7,5)$ & $166(\% 77,5)$ & $182(\% 85)$ & \\
\hline \multirow{2}{*}{$\begin{array}{l}\text { Hipertansiyon } \\
\text { öyküsü }\end{array}$} & Var & $0(\% 0,0)$ & $20(\% 9,3)$ & $20(\% 9,3)$ & \multirow{2}{*}{0,378} \\
\hline & Yok & $17(\% 8)$ & $177(\% 82,7)$ & $194(\% 90,7)$ & \\
\hline \multirow{2}{*}{$\begin{array}{l}\text { Gestasyonel } \\
\text { diyabet }\end{array}$} & Var & $4(\% 1,8)$ & $24(\% 11,3)$ & $28(\% 13,1)$ & \multirow{2}{*}{0,250} \\
\hline & Yok & $13(\% 6,1)$ & $172(\% 80,8)$ & $185(\% 86,9)$ & \\
\hline \multirow{3}{*}{$\begin{array}{l}\text { GBS enfeksiyonlu } \\
\text { bebek öyküsü }\end{array}$} & Var & $0(\% 0,0)$ & $0(\% 0,0)$ & $0(\% 0,0)$ & \multirow{3}{*}{1,00} \\
\hline & Yok & $17(\% 7,9)$ & $194(\% 90,7)$ & $211(\% 98,6)$ & \\
\hline & Bilinmiyor & $0(\% 0,0)$ & $3(\% 1,4)$ & $3(\% 1,4)$ & \\
\hline
\end{tabular}

*Ki kare testi

Tablo 4. Gebelerin Kullandıkları Doğum Kontrol Yöntemlerinin GBS Üremesi İle Karșılaștırılması

\begin{tabular}{|c|c|c|c|c|c|}
\hline \multirow{2}{*}{\multicolumn{2}{|c|}{ Değişken }} & \multicolumn{2}{|c|}{ GBS üreme } & \multirow[t]{2}{*}{ Toplam } & \multirow[t]{2}{*}{ p değeri* } \\
\hline & & Var & Yok & & \\
\hline \multirow{4}{*}{$\begin{array}{l}\text { Doğum kontrol } \\
\text { yöntemi }\end{array}$} & OKS & $1(\% 0,4)$ & $21(\% 9,8)$ & $22(\% 10,2)$ & \multirow{4}{*}{0,055} \\
\hline & RİA & $3(\% 1,4)$ & $22(\% 10,3)$ & $25(\% 11,7)$ & \\
\hline & Diğer & $10(\% 4,7)$ & $61(\% 28,5)$ & $71(\% 33,2)$ & \\
\hline & Kullanmiyor & $3(\% 1,4)$ & $93(\% 43,5)$ & $96(\% 44,9)$ & \\
\hline
\end{tabular}

*Ki kare testi

Sürüntü örrneklerinde GBS üreyen ve üremeyen kadınların özelliklerinin karşılaştırılması Tablo 6 da gösterilmiştir.

Olguların ilk gebelikteki yaşları ile GBS üremesi arasında istatistiksel olarak anlamlı bir fark saptand $1(p=0,042)$. İlk gebelik yaş1 yüksek olan gebelerde GBS üremesi daha fazlaydı. GBS üremesi ile yaş, evlendiği yaş, evlilik süresi, menarş yaşı, gebelik haftası ve gestasyonel öyküleri (gravida, parite, yaşayan çocuk, ölen çocuk ve küretaj) arasında ilişki saptanmadi $(\mathrm{p}>0.05)$. 
Tablo 5. Gebelerin Doğum Kontrol Yöntemi Kullanma Durumlarının GBS Üremesi ile Karșılaștırılması

\begin{tabular}{|c|c|c|c|c|c|}
\hline \multirow{2}{*}{\multicolumn{2}{|c|}{ Değişken }} & \multicolumn{2}{|c|}{ GBS üreme } & \multirow[t]{2}{*}{ Toplam } & \multirow[t]{2}{*}{ p değeri* } \\
\hline & & Var & Yok & & \\
\hline \multirow{3}{*}{$\begin{array}{lr}\text { Doğum } & \text { kontrol } \\
\text { yöntemi kullanımı }\end{array}$} & Kullanıyor & $14(\% 6,5)$ & $104(\% 48,6)$ & $118(\% 55,1)$ & \multirow{3}{*}{0,019} \\
\hline & Kullanmiyor & $3(\% 1,4)$ & $93(\% 43,5)$ & $96(\% 44,9)$ & \\
\hline & Toplam & $17(\% 7,9)$ & $197(\% 92,1)$ & $214(\% 100)$ & \\
\hline
\end{tabular}

*Ki kare testi

Tablo 6. Gebelerin Vajinal ve Anorektal Bölgelerinde GBS Dıșında Üreyen Mikroorganizmaların Dağılımı

\begin{tabular}{|c|c|c|}
\hline Mikroorganizma & Sayı & Yüzde \\
\hline Candida spesies & 17 & $\% 7,94$ \\
\hline Candida albicans * & 43 & $\% 20,9$ \\
\hline Lactobasillus spesies* & 18 & $\% 8,41$ \\
\hline Basillus spesies * & 2 & $\% 0,93$ \\
\hline E. coli * & 32 & $\% 14,95$ \\
\hline Enterococcus aerogenes & 2 & $\% 0,93$ \\
\hline Enteroccus faecalis & 55 & $\% 25,70$ \\
\hline Staf. Epidermidis* & 59 & $\% 27,57$ \\
\hline Staf. Aureus * & 6 & $\% 2,80$ \\
\hline Kagülaz negatif stafilakok * & 12 & $\% 5,60$ \\
\hline Lactobasillus basillus * & 1 & $\% 0,46$ \\
\hline Klamidya pnömoni & 4 & $\% 1,86$ \\
\hline Streptokokus spesies * & 2 & $\% 0,93$ \\
\hline Beta hemolitik streptokok * & 1 & $\% 0,46$ \\
\hline Sakromiçes spesies & 1 & $\% 0,46$ \\
\hline
\end{tabular}

* Normal vajinal flora bakterileri

Gebelerin vajinal ve anorektal bölgelerinde GBS dışında üreyen mikroorganizmalar Tablo 6 da gösterilmiştir.

\section{TARTIŞMA}

GBS taşıyıcılığı ırk, yaşanılan coğrafi bölge, sosyokültürel alışkanlıklara bağlı olarak oldukça farkl1lıklar gösterir. Stoll BJ ve Schuchat, 1998'de yaptığı bir metaanalizde; gelişmekte olan ülkelerde yapılmış 34 çalışmayı incelenmişler ve genel kolonizasyonun $\quad \% 17.8 \quad$ olduğunu saptamışlardır. Ayrıca Ortadoğu ve Kuzey Afrika'da gebelerin \%22'sinde, Asya'da (Pasifik) \%19'unda, Güney Afrika'da \%19'unda, Hindistan ve Pakistan'da \%12'sinde ve Güney Amerika'da \%14'ünde kolonizasyon olduğunu bulmuşlardır (4). Ülkemizde yapılan çalışmalarda ise; Kireçci ve ark. Kahramanmaraş'da 97 gebe üzerinde yaptığı araştırmada, vajinal GBS kolonizasyonunu \%33 bulmuşlardır (5). Gül ve ark. 2005 yllında 150 gebe üzerinde yaptığ çalışmada GBS kolonizasyonu \%3 saptamışlar (6). Karadeniz ve ark. 1996 yilında, İstanbul'da, 200 doğum eylemi başlamış gebe 
üzerinde yaptığı çalışmada GBS kolonizasyonu $\% 8$ bulmuşlardır (7). Bizim çalışmamızda ise bu oran \%7.9 idi. Çalışmamızdaki GBS üreme oranı ülkemizdeki diğer çalışmalarla paralellik göstermektedir.

Hammoud ve ark. yaptığı çalışmada, GBS üreyen gebelerin yaş ortalaması $28.9 \pm 5.9$ olarak izlenmiş ve yaş ile kolonizasyon arasında ilişki saptanmamıştır (8). Aynı şekilde, 2009 yilında Matee ve ark. Tanzanya'da yaptığı çalışmada da GBS kolonizasyonu ve yaş arasında ilişki bulunamamıştır (9). Çalışmamızda gebelerin yaş ortalaması $29,48 \pm 5,58$ 'di ve yaş ile GBS kolonizasyonu arasında bir ilişki saptanmadi. $\mathrm{Bu}$ çalışmadaki bulgularda da yaş ile GBS kolonizasyonu arasında ilişki bulunamamış olup, bu sonuç literatür ile uyumlu idi.

Çalışmamızda, ilk gebelik yaşı yüksek olan kadınlarda GBS üremesi anlamlı bir şekilde daha yüksekti $(p<0.05)$. Literatürde ilk gebelik yaşı ile ilgili çalışmalara rastlanamad. $\mathrm{Bu}$ konuda çalışmalar yapılması gerekliliğ i gözlenmektedir.

Çalışmamızda gebelerin gestasyonel öyküleri (gravida, parite vs.) ile GBS üreme durumları arasında ilişki saptanmadı. Bizim çalışmamıza paralel olarak; Dechen ve ark. Hindistan'da 524 gebe üzerinde yaptıkları çalışmada gravida ve GBS kolonizasyonu arasında ilişki bulunmamıştır (10). Gül ve ark. GBS kolonizasyonu ile gebelerin doğum sayıları arasında ilişki saptanmamıştır (6). Bu çalışmanın aksine, Kim ve ark. yaptığı 2624 gebeyi kapsayan çalışmada, GBS kolonizasyonunun ilk gebelikte (Gravida:1, Parite:0) anlamlı derecede yüksek olduğu gözlenmiştir (11). Hammoud ve ark. 1120 gebe üzerinde yaptıkları araştırmada ise 2'den fazla pariteye sahip kadınlarda GBS kolonizasyonu anlamlı oranda yüksek saptanmıştır (8).

Çalışmamızda gebelerin sosyoekonomik düzeyleri ile GBS kolonizasyonu arasında bir ilişki bulunamadı. Bizim çalışmamızı destekler nitelikte; Karakuş ve arkadaşları yaptıkları çalışmada, sosyo-ekonomik düzey ile GBS kolonizasyonu arasında bir ilişki bulamamışlardır (12). Mavenyengwa ve ark. yaptığı bir çalışmada ise sosyo-ekonomik düzey ile kolonizasyon arasında ilişki bulunmazken; kırda yaşayanlarda (\%66.7) şehirde yaşayanlara (\%47.7) oranla anlamlı bir biçimde yüksek GBS kolonizasyonu görülmüştür (13). Çalışmamızın aksine; Regan ve arkadaşları yaptıkları kapsamlı çalışmada, sosyoekonomik düzey ile GBS kolonizasyonu açısından zayıf bir ilişkinin söz konusu olduğunu belirtmişlerdir (14). Eren ve arkadaşları ise orta düzeyde sosyoekonomik seviyeye sahip olanlarda, anlamlı biçimde yüksek kolonizasyon saptamışlardır (15). Bu konuda kapsamlı çalışmalara ihtiyaç vardır.

Çalışmamızda gebelerin \%83.2' sinin $(\mathrm{n}=178)$ menstrüel sikluslarının düzenli, $\% 16.8^{\prime}$ sinın $(n=36)$ düzensiz olduğu izlendi. Kadınların siklus düzenleriyle GBS üreme durumları arasında istatistiksel olarak anlamlı düzeyde fark vard1 $(p<0.05)$. Menstrüel siklusları düzensiz olan kadınlarda GBS üreme durumu (\%20), düzenli olanlara göre $(\% 6.5)$ daha yüksekti. Literatürde GBS kolonizasyonu ile menstirüel siklus arasında ilişki bildiren çalışma bulunamadı. Çalışmamız, gebelik öncesi mentrüel siklus düzensizliği ile GBS kolonizasyonu arasındaki ilişkiyi bildiren ilk çalışma olması açısından önemlidir.

Çalışmamızda, gebelerin \%91.1' i sigara kullanmıyordu ve sigara içme durumlarıyla GBS üreme durumları arasında istatistiksel olarak anlamlı bir ilişki yoktu. Bizim çalışmamıza paralel olarak; Kim ve ark. 2624 gebe üzerinde yaptıkları çalışmada sigara kullanımı ile GBS kolonizasyon sıklı̆̆ arasında bir ilişki bulunamamıştır (11). Bizim çalışmamızın aksine; Terry ve arkadaşları 543 gebede yaptıkları çalışmada, sigara kullanan gebelerde GBS kolonizasyonunu \%33.1 bulmuşlardır (16). Sigara kullanımının GBS kolonizasyonuna etkisi konusunda daha geniş çalışmalara ihtiyaç olduğu görülmektedir. 
Çalışmamızda gebelerin \%55,1' i (n=118) gebelik öncesi doğum kontrol yöntemlerinden birini kullanmaktayd1. Bunların \%10.2' si $(n=22)$ yöntem olarak oral kontraseptif, \%11.7' i $(n=25)$ RİA, \%33.2' si $(n=71)$ diğer yöntemleri kullanıyordu. Doğum kontrol yöntemi kullanan gebelerin \%11.8' inde GBS ürerken, kullanmayanlarda bu oran \%3.1 idi. Doğum kontrol yöntemi kullanan kadınlarda GBS üreme durumu istatistiksel olarak anlamlı biçimde daha yüksekti ( $\mathrm{p}<0.05)$. Morris ve ark. 291 kadın üzerinde yaptığı çalışmada; oral kontraseptif ve tampon kullanımının GBS kolonizasyonu üzerinde etkisi olmadığ saptanmıştır (17). Eren ve ark. yanısıra, Gül ve ark. yaptığı araştırmada da RİA kullanımının GBS kolonizasyonuna etkisi saptanamamıştır. $\mathrm{Bu}$ konuda geniş kapsamlı çalışmalara ihtiyaç duyulmaktadır $(6,15)$.

Hipertansiyonu mevcut olan gebelerimizin hiçbirinde GBS üremesi olmazken $(\% 0)$, diyabetli gebelerimizin \%14.2' sinde GBS üremesi saptandı. Kadınların hipertansiyon öyküleri ile GBS üreme durumları arasında istatistiksel olarak anlamlı bir ilişki yoktu. Çalışmamızda, gestasyonel diyabeti olan gebelerin GBS kolonizasyonu, diyabeti olmayan gebelere göre 2,21 kat yüksek bulunmuştur. Fakat GBS üremesi ile gestasyonel diyabet arasında istatistiksel olarak anlamlı bir ilişki bulunamamıştır $(\mathrm{p}=0,25)$. Bizim bulgularımızın aksine; Bey ve ark. gestasyonel diyabet ve GBS kolonizasyonu arasında anlamlı bir ilişki saptamışlardır. Gestasyonel diyabetlilerde \%31.7 kolonizasyon saptarken, kontrol grubunda bu oranı \%19.0 bulmuşlardır (18). Akhlaghi ve ark., 93 (50' si diyabetli, 43' ünün diyabeti yok) gebeyi kapsayan çalışmada, gestasyonel diyabetli gebelerin \%20'sinde GBS üremiştir. Gestasyonel diyabeti olan kadınlar olmayanlara göre rektal GBS kolonizasyonu açısından daha yüksek riskli bulunmuştur (19). Hammoud ve ark. 1120 gebeyi kapsayan çalışmasında ise, diyabet ve hipertansiyonun GBS kolonizasyonu ile ilişkisi saptanmamıştır (8). Bazı çalışmalarda diyabetes mellitus ile
GBS kolonizasyonu arasında ilişki istatistiksel olarak anlamlı bulunmasa da genellikle diyabetli gebelerde daha fazla bulunmuştur. $\mathrm{Bu}$ durum diyabetin immün sistemi bask1lamasından kaynaklanabilir. Son y1llarda yeni araştırmalar yenidoğan GBS sepsisinin önlenmesi için anne aşılanmasına yönelik ilerlemektedir (20).

Sonuç olarak, 214 gebenin 17' sinde (\%7.9) GBS üredi; 8 gebede (\%47.1) sadece vajinada, 2 (\%11.7) gebede sadece anorektal bölgede üreme olurken, 7 (\%41.2) gebede ise her iki bölgede de üreme oldu. Gebelerimizden alınan kültür örneklerinde GBS dışında \%27.5' inde stafilokokkus epidermidis, \%25.7' sinde enterococcus faecalis, \%20.9' unda candida albicans üredi. Menstrüel siklusları düzensiz olan kadınların \%20' sinde GBS ürerken, menstrüel siklusu düzenli olanların $\% 6.5$ ' inde GBS üremiştir. Gebelik öncesi doğum kontrol yöntemi kullanan kadınlarda GBS üremesi istatistiksel olarak anlamlı düzeyde yüksekti (\%11.8). İlk gebelik yaşı yüksek olan kadınlarda GBS üreme oranı daha yüksekti. İlk gebelik yaşı yüksek olan, menstrüel siklus düzensizliği yaşayan ve doğum kontrol yöntemi kullanan kadınlarda GBS üremesinde artı̧̧ gözlemledik. Bu nedenle bu parametreleri esas alan daha geniş kapsamlı çalışmalara ihtiyaç vardır.

Ülkemizde CDC tavsiyelerine uyulması ve gelişmiş birçok ülkede uygulanan yenidoğanın erken başlangıçlı enfeksiyonlarını önlemek için gebe tarama programları arasinda yer alan GBS taramasinın rutin gebe izlem programına dâhil edilmesi gerekmektedir.

Çalışmanın kısıtlılıkları: Üremesi olan gebelerin doğum sonuçlarının belirlenmemesidir.

\section{KAYNAKLAR}


1. Gibbs RS, Schrag S, Schuchat A. Perinatal infections due to group B streptococci. Obstetrics \& Gynecology. 2004;104(5, Part 1):1062-76.

2. Verani JR, McGee L, Schrag SJ. Prevention of perinatal group B streptococcal disease: Revised guidelines from CDC. Atlanta;2010.

3. Cagno CK, Pettit JM, Weiss BD. Prevention of perinatal group B streptococcal disease: updated CDC guideline. American family physician. 2012;86(1):59-65.

4. Stoll BJ, Schuchat A. Maternal carriage of group B streptococci in developing countries. The Pediatric infectious disease journal. 1998;17(6):499-503.

5. Kireçci E, Özer A, Arıkan DC, Gül M. Group B Streptococcal Vaginal Colonization in the Third Trimester of Pregnancy. Gynecology Obstetrics \& Reproductive Medicine. 2010;16:1448.

6. Gül H, Dede M, Avcı İ, Eyigün C, Pahsa A. Üçüncü trimestr hamilelerde vaginal grup B streptokok kolonizasyonu. Klimik Derg. 2005;18(1):27-9.

7. Karadeniz M, Ekmekçioğlu YA, Öztürk R, Tokuç G, Özgüner A. Gebelerde ve yenidoğan Bebeklerde Grup B Streptokok (St. Agalactiae) Sıklığının Araştıtrılması. J Kartal TR. 1998; (9)1:683-6.

8. Hammoud M, Thalib L, Maiyegun S. The epidemiology of group B streptococcal colonization among obstetrical and newborn populations in Kuwait. International Journal of Gynecology and Obstetrics. 2015;76:315-6.

9. Matee MI, Massawe FA, Lyamuya EF. Maternal and neonatal colonisation of group B streptococcus at Muhimbili National Hospital in Dar es Salaam, Tanzania: prevalence, risk factors and antimicrobial resistance. BMC public Health. 2009;9(1):1.

10. Dechen TC, Sumit K, Ranabir P. Correlates of vaginal colonization with group $\mathrm{B}$ streptococci among pregnant women. Journal of global infectious diseases. 2010;2(3):236.

11. Kim EJ, Oh KY, Kim MY, Seo YS, Shin J-H, Song YR, et al. Risk factors for group B streptococcus colonization among pregnant women in Korea. Epidemiology and health. 2011;33:e2011010.

12. Karakuş M, Karaca DY, Günçiner Ş. Gebelerde grup B streptokok kolonizasyonu ve antimikrobiyal direnç paterni. Ege Tip Dergisi. 2007;46(3):151-4.

13. Mavenyengwa RT, Afset JE, Schei B, Berg S, Caspersen T, Bergseng H, et al. Group B Streptococcus colonization during pregnancy and maternal-fetal transmission in Zimbabwe. Acta obstetricia et gynecologica Scandinavica. 2010;89(2):250-5.
14. Regan JA, Klebanoff MA, Nugent RP. The epidemiology of group B streptococcal colonization in pregnancy. Obstetrics \& Gynecology. 1991;77(4):604-10.

15. Eren A, Kucukercan M, Oguzoglu N, Unal N, Karateke A. The carriage of group B streptococci in Turkish pregnant women and its transmission rate in newborns and serotype distribution. Turk J Pediatr. 2005;47(1):28-33.

16. Terry R, Kelly F, Gauzer C, Jeitler M. Risk factors for maternal colonization with group $\mathrm{B}$ beta-hemolytic streptococci. The Journal of the American Osteopathic Association. 1999;99(11):571-3.

17. Morris C, Morris DF. Normal'vaginal microbiology of women of childbearing age in relation to the use of oral contraceptives and vaginal tampons. Journal of clinical pathology. 1967;20(4):636.

18. Bey M, Pastorek JG, Miller JM. Group B streptococcal colonization in the diabetic gravida patient. American journal of perinatology. 1992;9(05/06):425-7.

19. Akhlaghi F, Hamedi A, Nasab MN. Comparison of group B streptococcal colonization in the pregnant diabetic and non-diabetic women. Acta Medica Iranica. 2009;47(2):103-8.

20. Schrag SJ. Maternal Immunization to Prevent Neonatal Group B Streptococcal Disease: New Progress and Promise. Obstetrics \& Gynecology. 2016;127(2):199-201. 